\title{
PERFORMANCE EVALUATION OF A MECHANISM FOR GREEN ONION HANDLING
}

\author{
Mayhoub, M. A."; E. A. El-Sahhar*; A. G. El-Kabany* and A. A. Abdel-Hafez ${ }^{* *}$
}

\section{ABSTRACT}

The objectives of this study were to design and evaluation performance of mechanism for green onion crop handling, as well as, improving the crop quality based on the suggested handling system. However, the suggested handling system consists of feeding unit, trimming unit which based on rotary cutting mechanism, antioxidant unit and tying unit. The following technical parameters had been considered to evaluate the suggesting mechanism: feeding belt speed, feeding rate, cutting disc speed, tying position of onion bundle relative to the cutting disc, angle of cutting disc and discharge rate of ascorbic acid. However, the following technical indicators had been estimated such as machine productivity, trimming efficiency, cutting offset angle of plants, the quality of the final product and the costs of green onion produced by mechanism system. Results indicated that the machine productivity was found to be $316.2 \mathrm{~kg} / \mathrm{h}$, handling system efficiency was $75.89 \%$, the trimming efficiency was $89.15 \%$, cutting offset angle of plants was $22^{\circ}$, at $12.5 \mathrm{~cm} / \mathrm{s}$ feeding-belt speed and when $5.6 \mathrm{~kg} / \mathrm{min}$ feeding rate. With operated at $5.11 \mathrm{~m} / \mathrm{s}$ cutting disc speed, the optimum tying position during trimming process is $7.5 \mathrm{~cm}$, the wilting coefficient was $(0.09 \mathrm{~mm} /$ day $)$ at discharge rate of 5 $\mathrm{l} / \mathrm{h}$ and handling machine reduced the cost of green onion trimming to 1 : 2.67 as compared with manual method.

Keywords: Postharvest, Handling processes, Cutting operation, Trimming operation, Cutting efficiency.

\section{INTRODUCTION}

reen onion crop is rich of components to use as a natural
medicine activities and helps in expelling sputum (phlegm)
(Takano, 2004). Therefore, the cultivated area had been
expanded with about $38.31 \%$ (from 6063 to 8386 fed.) with an increment

${ }^{*}$ Ag. Eng. Department, Faculty of Agriculture, Ain Shams University

${ }^{* *}$ Horticulture Department, Faculty of Agriculture, Ain Shams University 
ratio of the unit area productivity of about $26.41 \%$ (from 53039 to 67046 ton), in a wide narrow range time 2003 to 2005, according to Economic Affairs Sector (2004 and 2006). Due to, the standards of quality in the international markets, several problems of vegetable precuts export had been occurred, due to the leakage of handling processes as: manual trim, personal experience and septic tools. Mishra and Gamage (2007) reported that vegetables are sorted and graded for marketing and have a role in protecting and enhancing product quality. Moreover, USDA (2008) reported that for onion crop (Allium cepa) all of the tops shall be evenly clipped to not more than 12 inches $(30.48 \mathrm{~cm})$ nor less than 8 inches $(20.32 \mathrm{~cm})$, and they reported that the commonly cultivated green onion should be cleaned by washing thoroughly with potable water to remove soil and sorted to remove any that are diseased or otherwise damaged. Habib et al (2001) reported that the cutting process of agricultural plants is more complicated than the cutting of engineering materials. This may be due to plants are non-homogeneous and nonisotropic materials. Kepner et al (1982) reported that a common way of applying cutting forces is by means of two opposed shearing elements which meet and pass each other with little or no clearance between them. Either one or both of the elements may be moving, and the motion may be liner with uniform velocity or rotary. Kanafojski and Karwowski (1976) reported that the plants have a specific (fibrous) structure resistance and the value of the work involved depend on the direction of cutting blades or stalks obtained. In other words they depend the positioning of the knife relative to the stalk, moreover, the friction angle $(\varphi)$ in two cases being equal and the resolution of forces that if the angle between cutting edge $(\alpha)$ more than $(2 \varphi)$, then the resultant acts in the direction of throwing out of the body, on the other hand, $\left(\alpha_{1}<\alpha<\varphi\right)$, then the resultant is directed in the opposite direction, this direction of is the indispensable prerequisite of making a cut. Sitkei (1986) reported that with increasing cutting velocity, preliminary compaction decreases as a result of the material's inertia and plastic behavior, whereby the energy requirements of cutting are lowered. The latter effect operates as follows; owing to the low velocity of deformation of plastic materials, impact loading by rapidly moving knife edge propagates only slowly in the material, i.e., is concentrated in the 
material found around the edge. Consequently, cutting may be affected with lower energy consumption.

\section{MATERIALS AND METHODS}

A handling mechanism (trimming, antisepsis, and tying), had been designed, constructed and evaluated in the Agricultural Machinery Laboratory, Department of Agricultural Engineering, Faculty of Agriculture, Ain Shams University, as presented in Fig. (1), to achieve the overall goals of this study. However, the main parts of the mechanism are: 1- Feeding unit: The feeding unit consists of a flax belt of $4 \mathrm{~mm}$ thickness; $100 \mathrm{~cm}$ length and $25 \mathrm{~cm}$ width. The feeding belt is driven with two drums having a diameter of $6 \mathrm{~cm}$ and length of $34 \mathrm{~cm}$, and rotating through four bearings bolted in the frame (Fig. 2). A V-belt and three pulleys are used to transmit the motion from an electric motor $(0.2 \mathrm{~kW})$ to the driver drum. The motor is provided with electric resistor to give revolution speeds of 20 and $80 \mathrm{rpm}$. A woody bar having $20 \mathrm{~cm}$ length, $10 \mathrm{~mm}$ width and $3 \mathrm{~cm}$ height is used as device to guide the plants to the cutting discs and to adjust the cutting length of the plants.

2- Trimming unit (Fig. 3): The trimming unit consists of two cutting discs made from steel-plate having a $15 \mathrm{~cm}$ diameter fixed on two axes with $20 \mathrm{~mm}$ diameter and $40 \mathrm{~cm}$ long rotating through four bearings bolted in the frame.

3- Frame: The frame was locally manufactured from steel angle with cross section dimensions of $4 \times 4 \times 0.4 \mathrm{~cm}$. The frame consists of three parts: the feeding belt carrier, the cutting discs carrier and the base motors. The feeding belt carrier frame was 56 x122 cm and height of 80 $\mathrm{cm}$. The cutting discs carrier dimensions are $30 \times 50 \mathrm{~cm}$ and fixed with the belt frame by welding with a distance of $60 \mathrm{~cm}$ from the belt frame and $10 \mathrm{~cm}$ from the cutting discs frame. The base motors frame was made from square steel bar sections $2 \times 2 \mathrm{~cm}$ and with dimensions of 30 width, 60 length and height of $50 \mathrm{~cm}$. 


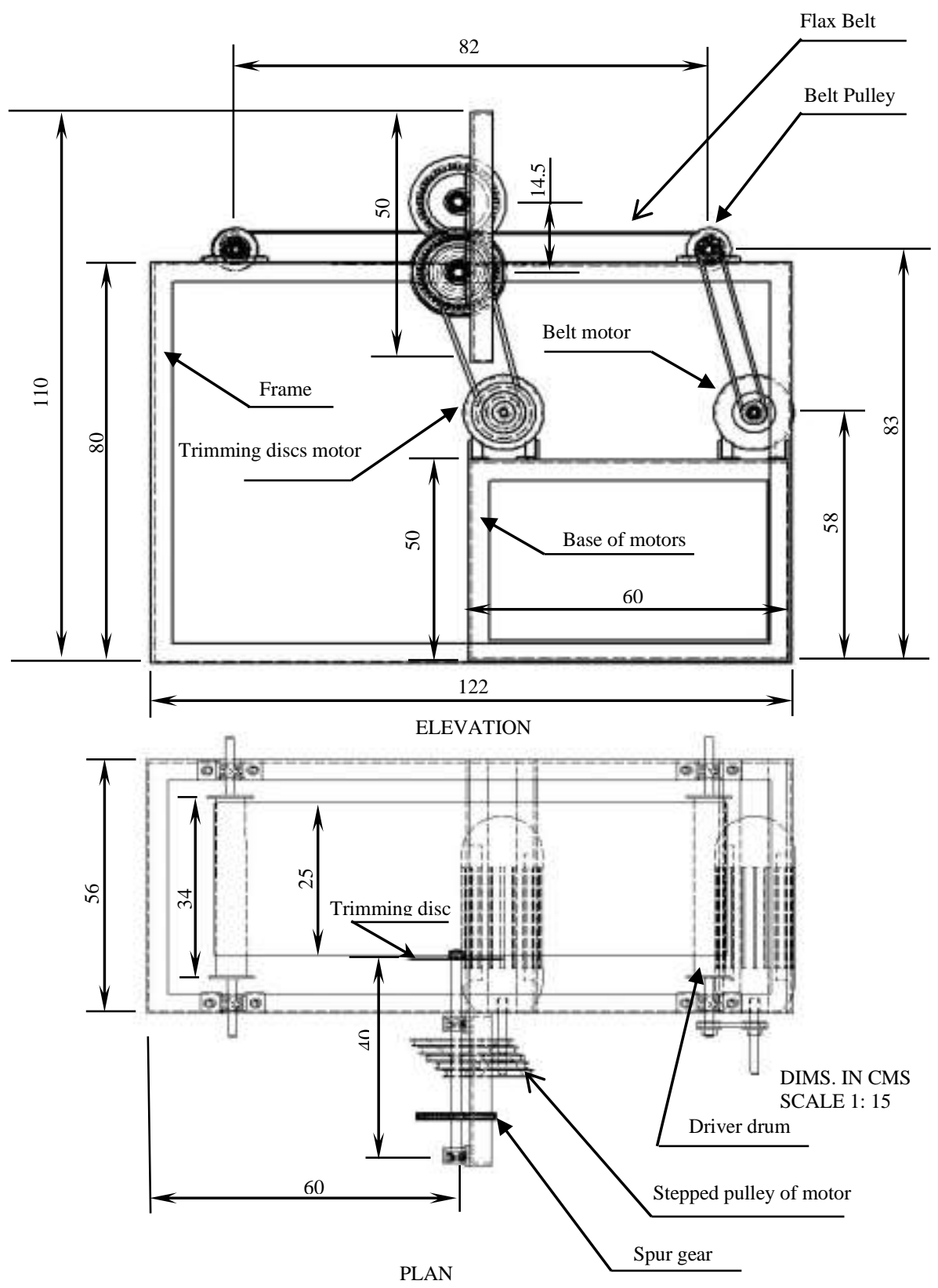

Fig. 1: The prototype of green onion handling mechanism. 


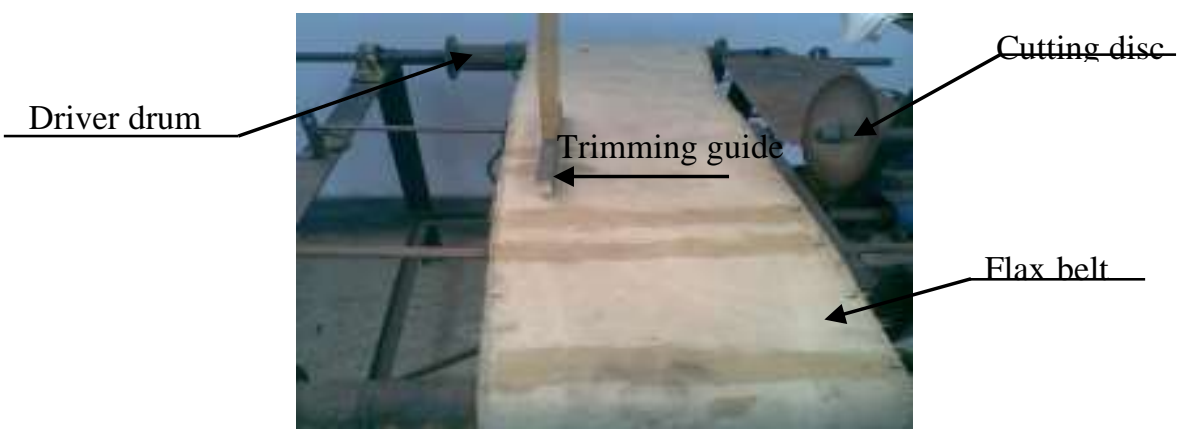

Fig. 2: Feeding belt

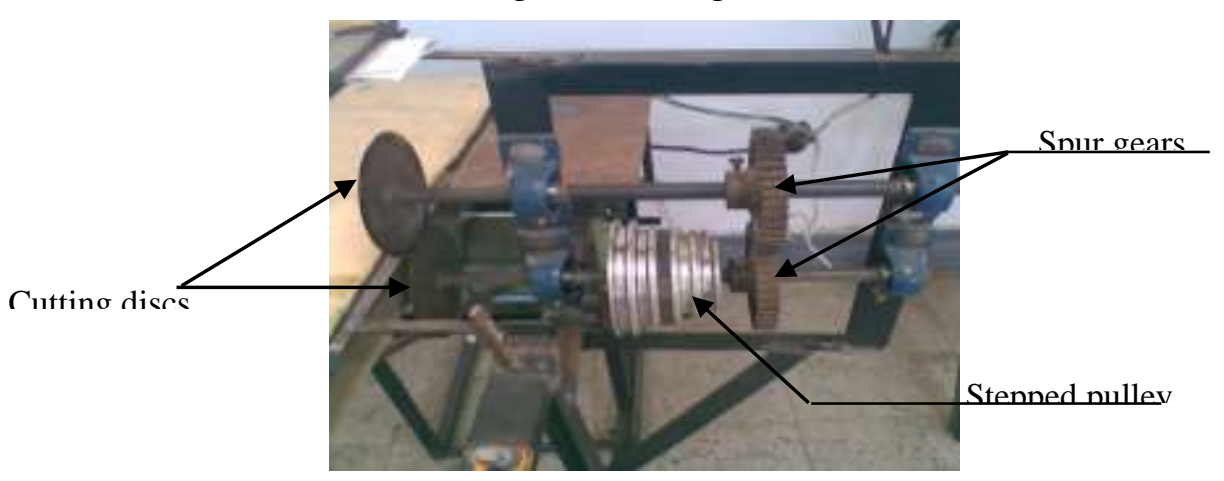

Fig. 3: Trimming unit and transmission mechanism.

4- Transmission mechanism for trimming unit: Two spur gears of 15 $\mathrm{cm}$ diameter, module $3.57 \mathrm{~mm}$, and a stepped pulley for 5 speeds are used to transmit the motion from electric motor to the cutting disc axis. The diameters of the first pulley are 161, 146, 131, 116 and $101 \mathrm{~mm}$, while those of second pulley are 46, 61, 76, 91 and $106 \mathrm{~mm}$ for step up ratios of 1:3.5, 1:2.4, 1:1.72, 1:1.27 and 1:.95 respectively.

5- Tying device (Fig. 4): A semi-mechanical tying device was used to tie the bundles for plants before and after trimming process, however, it consists of tie tape, knife, staples and handle ${ }_{\text {Handle }}$

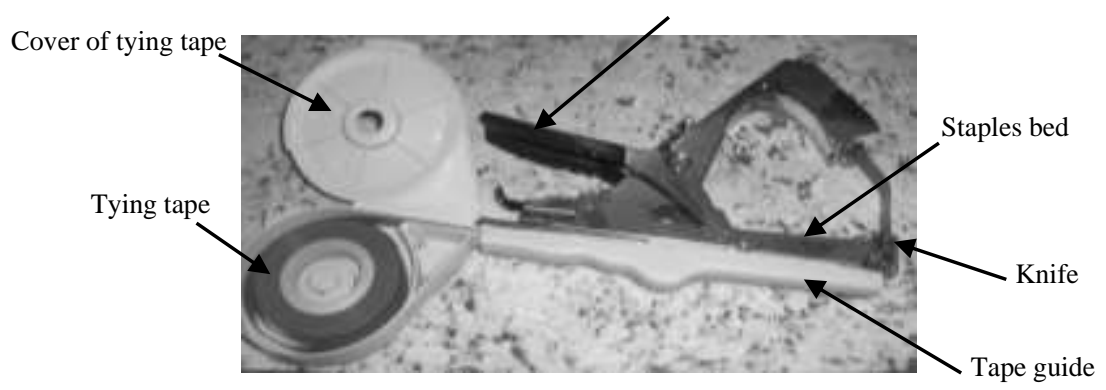

Fig. 4: Tying unit. 
6- Antisepsis unit: Antioxidant unit consists of a steel bar of $8 \mathrm{~mm}$ in diameter and height of $52 \mathrm{~cm}$ from cutting disc frame, ended with ring 10 $\mathrm{cm}$ in diameter. However, the bar was welded with the cutting disc frame. Ascorbic acid container made of plastic with $10 \mathrm{~cm}$ diameter had been constructed. The applied ascorbic acid with about $0.25 \%$ concentration had been added. The distance between the bottle and the cutting discs was adjusted tube $70 \mathrm{~cm}$; and the bottle was connected with a tube of $4 \mathrm{~mm}$ diameter with valve for control in discharge of solution, distance between the valve and the region of cutting (region of contribute discs) was $25 \mathrm{~cm}$.

7- Green onion crop: The variety of the onion crop ( $\underline{\text { Allium }} \underline{\text { cepa }}$ ) was used in this investigation. A representative sample of 52 plants was taken randomly, to measure dimensions and moisture content. The mean length of onion crop before trimming was $42.2 \mathrm{~cm}$, the mean diameter of plants was $5.5 \mathrm{~mm}$ and the mean thickness of green onion leaf was $0.55 \mathrm{~mm}$ (Figs. 5, 6 and 7). The moisture content of onion leaf was $86.4 \%$ and angle of friction was $29^{\circ}$ on steel plate.

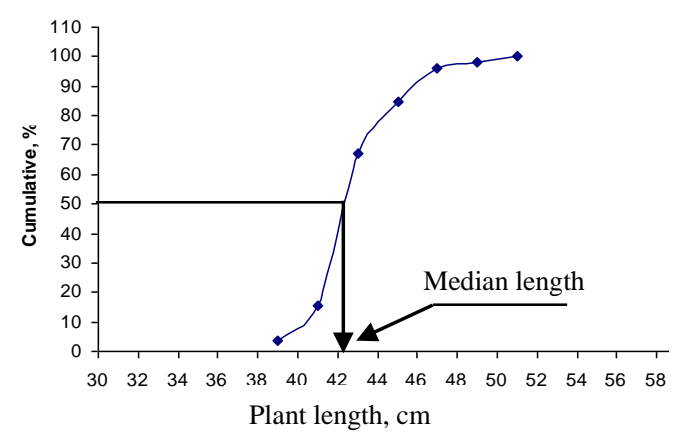

Fig. 5: the Cumulative distribution for green oninn lenothe

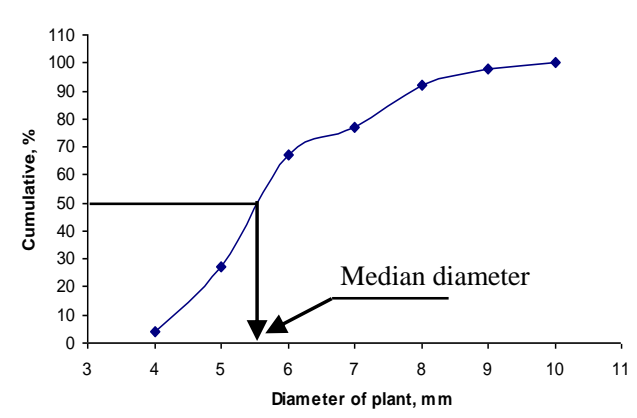

Fig. 6: The cumulative distribution for diameters of green onion.

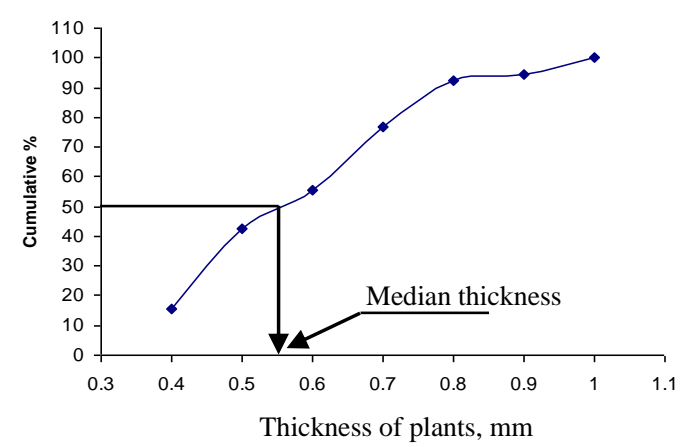

Fig. 7: The cumulative distribution tor green onıon thicknesses.

The $16^{\text {th }}$. Annual Conference of the Misr Society of Ag. Eng., 25 July, 20091574 


\section{Test procedure and treatments:}

The plan of the experiments was designed and carried out to study the effect of the following variables on the handling mechanism productivity, handling system efficiency, trimming efficiency, cutting offset angle of plants and quality of final product:

$>$ Feeding-belt speed: four levels of 20, 40, 60 and $80 \mathrm{rpm}(6.28,12.56$, 18.84 and $25.12 \mathrm{~cm} / \mathrm{s}$ ).

> Feeding rate: three levels of 5.2, 5.6, and $6 \mathrm{~kg} / \mathrm{min}$.

> Speed of cutting discs: three levels of $3.41,5.11$ and $7.1 \mathrm{~m} / \mathrm{s}$.

> Tying position of green onion bundle relative to the cutting disc: three levels of zero (without tying), $11 \mathrm{~cm}$ (with one tie) and $7.5 \mathrm{~cm}$ (with two ties).

$>$ Cutting angle between cutting discs (Fig. 8): three levels of 43, 51 and $60^{\circ}$.

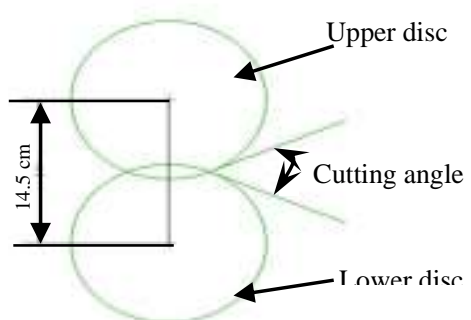

Fig. 8: the cutting angle between cutting discs.

Discharge rate of ascorbic acid: three levels of 1,3 , and $51 / \mathrm{hr}$.

Measurements and calculations:

1- Theoretical and actual mechanism productivities: Mechanism productivities had been calculated according to the following formula:

$$
\mathrm{P}_{\mathrm{t}}=W / T_{t}, \mathrm{P}_{\mathrm{a}}=W / T_{a}
$$

Where: $P_{t}$ : theoretical productivity, $\mathrm{kg} / \mathrm{hr} ; P_{a}$ : actual productivity, $\mathrm{kg} / \mathrm{hr}$; $W$ : weight of plant bundles during trimming operation, $\mathrm{kg} ; T_{t}$ : theoretical time calculated in onion bundle trimming operation, $\mathrm{hr}$; and $T_{a}$ : time consumed in onion bundle 
trimming treatment, to include: net time of cutting, sliding feeding belt and time of plant on belt, hr.

2- Handling system efficiency (\%): the handling system efficiency $\left(\eta_{s}\right)$ for each treatment was determined using the formula:

$$
\eta_{s}=P_{a} / P_{t} \times 100
$$

3- Trimming efficiency of the green onion crop (\%): the trimming efficiency $\left(\eta_{t}\right)$ for each treatment was determined using the formula:

$$
\eta_{t}=\left(1-\left(\frac{\sqrt{\frac{\sum\left(l-l_{\circ}\right)^{2}}{n}}}{l_{\circ}}\right)\right) \times 100
$$

Where: $l$ : length of plant after trimming, $\mathrm{cm} ; l_{o}$ : request length for each plant, $\mathrm{cm} ; n$ : number of plants in treatment.

4- Cutting offset angle of plants (deg.): the cutting offset angle of plants $(\theta)$ for each treatment was determined using the formula:

$$
\theta=\left(90-\sqrt{\frac{\sum\left(90-\theta_{\mathrm{o}}\right)^{2}}{n}}\right)
$$

Where: $\theta_{\circ}$ : Cutting angle of plant at cutting position, deg.; and $90^{\circ}$ : Request cutting angle.

5- Quality of green onion product: the quality of green onion was evaluated from the wilted zone-length time curve. A semi-logarithmic regression analysis was made in order to determine the value of the wilted coefficient "Wc" for all treatments, the slope of resulting line is the wilting coefficient.

6- Cost of green onion trimmed by handling mechanism: the cost per unit "L.E./ton" product was determined using the following equation according to (Awady 1978):

$$
\mathrm{C}=\mathrm{p} / \mathrm{h}(1 / \mathrm{y}+\mathrm{i} / 2+\mathrm{t}+\mathrm{m})+(\mathrm{W} * \mathrm{f})+\mathrm{s} / 144
$$

Where: C: Hourly cost in L.E., P: Price of the machine in L.E., h: Yearly operating hours, y: Life expectancy of the machine in years, i: Interest rate year, $\mathrm{t}$ : Taxes and overheads ratio, $\mathrm{m}$ : Maintenances and 
repairs ratio of the total investment, $\mathrm{W}$ : Total power of motors, $\mathrm{kW}$; $\mathrm{f}$ : Power unit price; s: Labors salary rate per month in L.E.; 144: Is the monthly average working hours.

\section{RESULTS AND DISCUSSION}

1- Feeding-belt speed: the values in Figs. (9 and 10) were obtained at speeds of feeding-belt from $6.28-25.12 \mathrm{~cm} / \mathrm{s}$. throughout this range, greater belt speed increased the machine productivity, decreased handling system efficiency, increased trimming efficiency and decreased cutting offset angle. The increase in machine productivity at higher feeding-belt speeds was due to increase the feeding of onion plants per time unit. On the other hand, the decrease in handling system efficiency values at higher belt speeds was due to the increase of time lost in adjusting the onion bundles on the belt. Moreover, the decrease in trimming efficiency at both lower and higher feeding-belt speeds was due to the increase of trimmed plant lengths, deflection plants, since the accumulated plants increased at lower feeding-belt speeds. Whilst, at the higher feeding-belt speeds, the trimmed plant lengths increased which resulted in the increased obliqueness plants since the impact plants with cutting discs increased. In addition, at lower feeding-belt speeds, the cutting offset angle increased due to increase leaves motion which gained from rotational speed of cutting disc compared with the decreased bulb motion which gained from the feeding-belt speed. The preferred feeding-belt speed of trimming machine to maximize the trimming efficiency was found to be $12.5 \mathrm{~cm} / \mathrm{s}$. as it resulted in higher handling system efficiency (75.89\%), lower cutting offset angle $\left(22^{\circ}\right)$ and consequently a higher trimming efficiency $(89.15 \%)$ than any of the other speeds.

2- Feeding rate: the effect of feeding rate on machine productivity, handling system efficiency, trimming efficiency and cutting offset angle are shown in Figs. (11 and 12), the use of feeding rates from $5.2-6$ $\mathrm{kg} / \mathrm{min}$. showed a slight increment in machine productivity, trimming efficiency and cutting offset angle and small decrease in handling system efficiency as the feeding rate increased. The insignificant increment in machine productivity and decrease in handling system efficiency were 
At feeding rate $5.6 \mathrm{~kg} / \mathrm{min}$ cutting disc speed $5.11 \mathrm{~m} / \mathrm{s}$., angle of cutting disc $51^{\circ}$ and without tying.

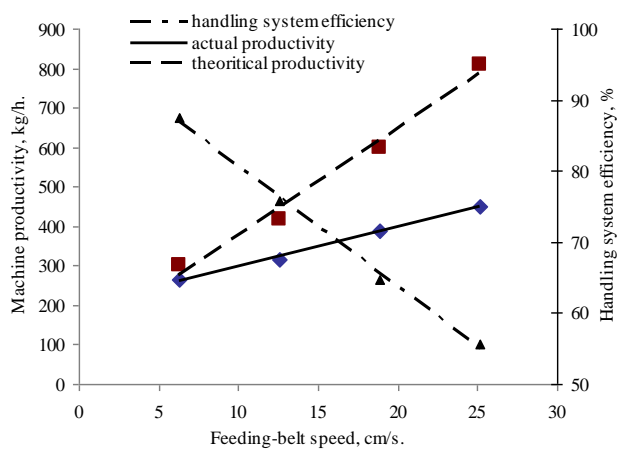

Fig. 9: Effect of feeding-belt speed on machine productivity and handling system efficiency.

At feeding-belt speed $12.5 \mathrm{~cm} / \mathrm{s}$, cutting disc speed $5.11 \mathrm{~m} / \mathrm{s}$,

angle of cutting disc $51^{\circ}$ and without tying

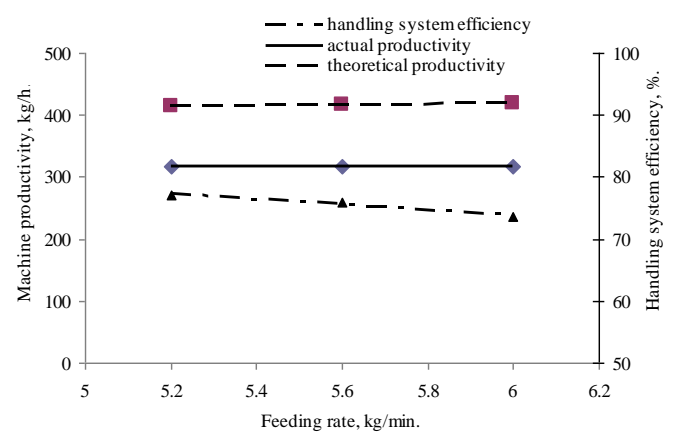

Fig. 11: Effect of feeding rate on machine productivity and handling system efficiency.
At feeding rate $5.6 \mathrm{~kg} / \mathrm{min}$, cutting disc speed $5.11 \mathrm{~m} / \mathrm{s}$., angle of cutting disc $51^{\circ}$ and without tying.

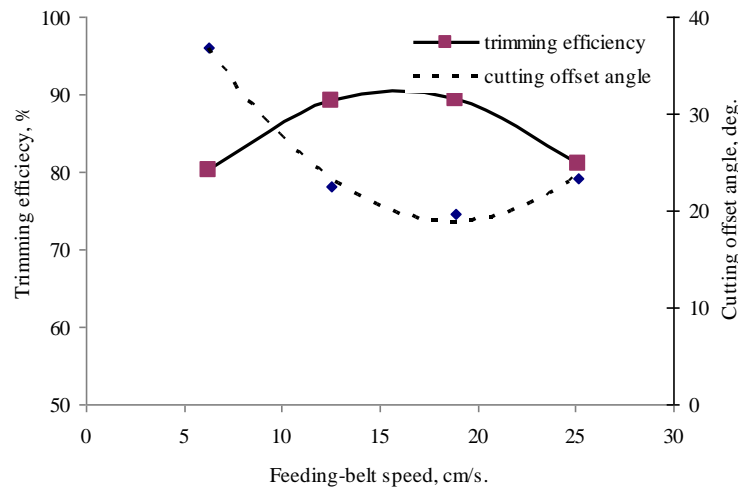

Fig. 10: Effect of feeding-belt speed on trimming efficiency and cutting offset angle.

At feeding-belt speed $12.5 \mathrm{~cm} / \mathrm{s}$, cutting disc speed $5.11 \mathrm{~m} / \mathrm{s}$, angle of cutting disc $51^{\circ}$ and without tying.

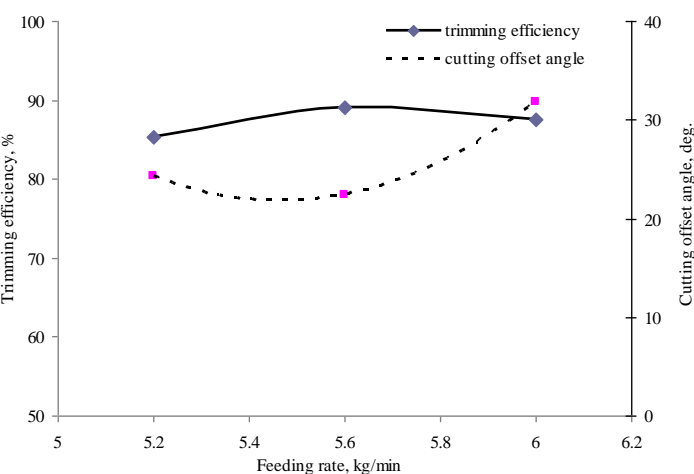

Fig. 12: Effect of feeding rate on trimming efficiency and cutting offset angle.

The $16^{\text {th }}$. Annual Conference of the Misr Society of Ag. Eng., 25 July, 20091578 
due to the little changing in feeding rate. In the same time, the decrease in handling system efficiency values at higher feeding rates was due to the increase of time lost in adjusting the onion bundles on the belt, as discussed before. Whilst the increase in both trimming efficiency and cutting offset angle was due to the increase of trimmed plant lengths and obliqueness plants which resulted in the increased accumulated plants at higher feeding rates as discussed before. The preferred feeding rate for trimming of green onion crop was found to be $5.6 \mathrm{~kg} / \mathrm{min}$ as it resulted in higher handling system efficiency (75.89\%), lower cutting offset angle $\left(22^{\circ}\right)$ and consequently a higher trimming efficiency $(89.15 \%)$.

3- Cutting disc speed: Figures (13 and 14) illustrate the results obtained with cutting disc speed. It can be noticed that with increase the cutting disc speed, the machine productivity no changed and slight decrease in handling system efficiency. This is attributed to constant both feedingbelt speed and feeding rate. Also, results showed that trimming efficiency and cutting offset angle increased as the cutting disc increased. Increased trimming efficiency and cutting offset angle values were due to the increased the lengths of trimmed plants which resulted in the increased obliqueness the plants since the gained motion from the rotational speed of cutting discs increased at higher cutting disc speeds. From the Fig. 14, a cutting speed of $5.11 \mathrm{~m} / \mathrm{s}$ was adequate to trim the green onion crop as it resulted in higher trimming efficiency $(89.15 \%)$ and lower cutting offset angle $\left(22^{\circ}\right)$.

4- Tying position: the results showed that the machine productivity and handling system efficiency are related to the tying position Fig. (15). Therefore, the handling system efficiency decreased from 75.89 to $71.1 \%$ by increasing tying position from $0-11 \mathrm{~cm}$ from the cutting discs. This is attributed to the decreased of the cutting time of green onion bundles in 7.5 and $11 \mathrm{~cm}$ tying positions. Moreover, Fig. 16 shows the trimming efficiency and cutting offset angle as affected by the tying position (without, 7.5 and $11 \mathrm{~cm}$ from the cutting disc). The results showed that the trimming efficiency and cutting offset angle at without tying were 
At feeding rate $5.6 \mathrm{~kg} / \mathrm{min}$, feeding-belt speed $12.5 \mathrm{~cm} / \mathrm{s}$, cutting

$$
\text { disc angle } 51^{\circ} \text { and without tying. }
$$

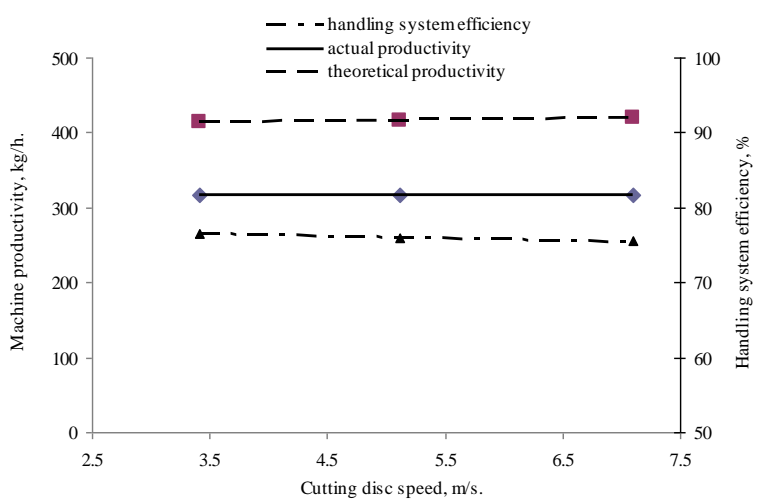

Fig. 13: Effect of cutting disc speed on machine productivity and handling system efficiency.

At feeding rate $5.6 \mathrm{~kg} / \mathrm{min}$, feeding-belt speed $12.5 \mathrm{~cm} / \mathrm{s}$, cutting disc speed $5.11 \mathrm{~m} / \mathrm{s}$ and cutting disc angle $51^{\circ}$

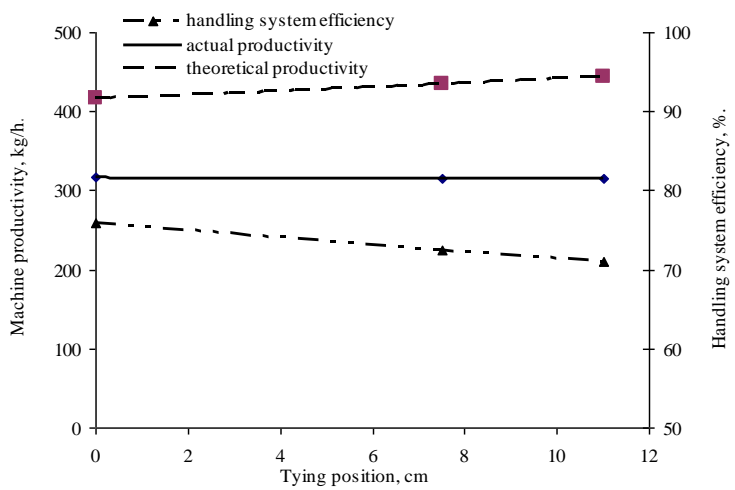

Fig. 15: Effect of tying position on machine productivity and handling system efficiency.
At feeding rate $5.6 \mathrm{~kg} / \mathrm{min}$, feeding-belt speed $12.5 \mathrm{~cm} / \mathrm{s}$

cutting disc angle $51^{\circ}$ and without tying.

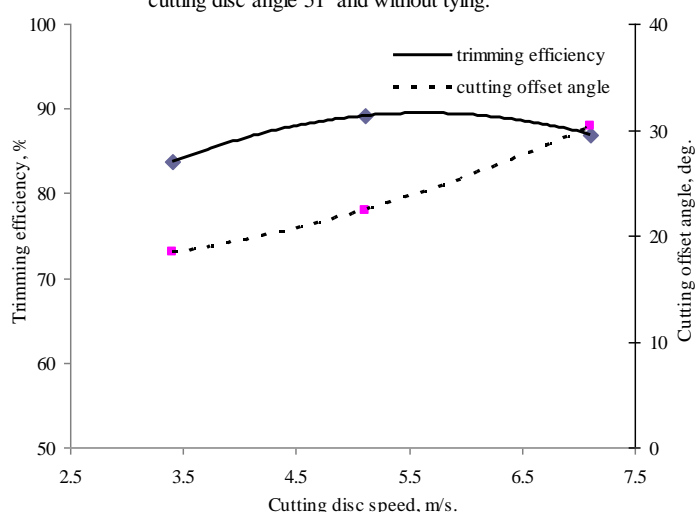

Fig. 14: Effect of cutting disc speed on trimming efficiency and cutting offset angle.

At feeding rate $5.6 \mathrm{~kg} / \mathrm{min}$, feeding-belt speed $12.5 \mathrm{~cm} / \mathrm{s}$ cutting disc speed $5.11 \mathrm{~m} / \mathrm{s}$ and cutting disc angle $51^{\circ}$

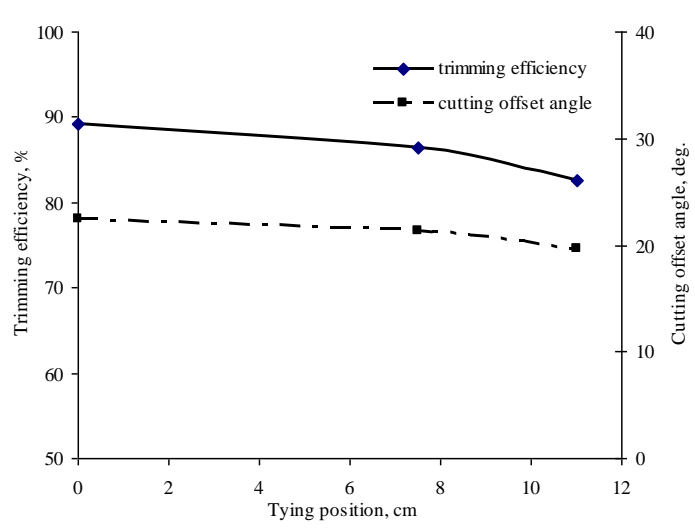

Fig. 16: Effect of tying position on trimming efficiency and cutting offset angle.

The 16 $6^{\text {th }}$. Annual Conference of the Misr Society of Ag. Eng., 25 July, 2009 
more than at $7.5 \mathrm{~cm}$ tying position by $(3.12 \%)$ and $(4.76 \%)$, respectively and more than at $11 \mathrm{~cm}$ tying position by $(7.85 \%)$ and $(15.79 \%)$, respectively. The difference between the trimming efficiency at without tying and $7.5 \mathrm{~cm}$ tying position is too small, compared with the difference between $11 \mathrm{~cm}$ tying position. This suggests that there is little gained from the tying of bundles at position of zero up to $11 \mathrm{~cm}$. therefore , the optimum tying position during trimming process is $7.5 \mathrm{~cm}$.

5- Angle between cutting discs: the effect of angle between cutting discs on machine productivity, handling system efficiency, trimming efficiency and cutting offset angle shown in Figs. (17 and 18). The results showed that the theoretical productivity decreased and handling system efficiency increased with increasing the angle between cutting discs (Fig. 17), owing to with increase angle between cutting discs the intersection between cutting discs increased and the plants need more time to cut. Moreover, the trimming efficiency decreased at the lower and higher angles (Fig. 18), due to, the resolution of forces on discs and plants during cutting, arising from resultant in oppsit cutting dirction to bolck cutting operation and with travel the belt, the plants deflection in cutting, to accomplish decreased trimming efficiency and increased cutting offset angle at this angles. The refere, the optimum angle between cutting discs during trimming process is $51^{\circ}$ as it resulted in higher trimming efficiency (89.2 $\%)$ and lower cutting offset angle $\left(22^{\circ}\right)$.

6- Effect of ascorbic acid discharge on the quality: the wilting coefficient was evaluated from wilting time curve. A semi-logarithmic regression analysis was made in order to determine the value wilting coefficient "Wc". For all experiments, the slope of the resulting line is the wilting coefficient as shown in Fig. (19) the results showed that the wilting coefficient decreased from $(0.47 \mathrm{~mm} /$ day $)$ at without antioxidant to $(-0.09 \mathrm{~mm} /$ day $)$ at discharge rate of $5 \mathrm{l} / \mathrm{h}$.

\section{7- Cost analysis:}

Cost per hour "C" $=1500 / 750(1 / 5+0.12 / 2+0.05+0.1)+0.2 *(0.26+$ $0.2)+800 / 144=6.47$ L.E. $/$ h. 
At feeding rate $5.6 \mathrm{~kg} / \mathrm{min}$, feeding-belt speed $12.5 \mathrm{~cm} / \mathrm{s}$,

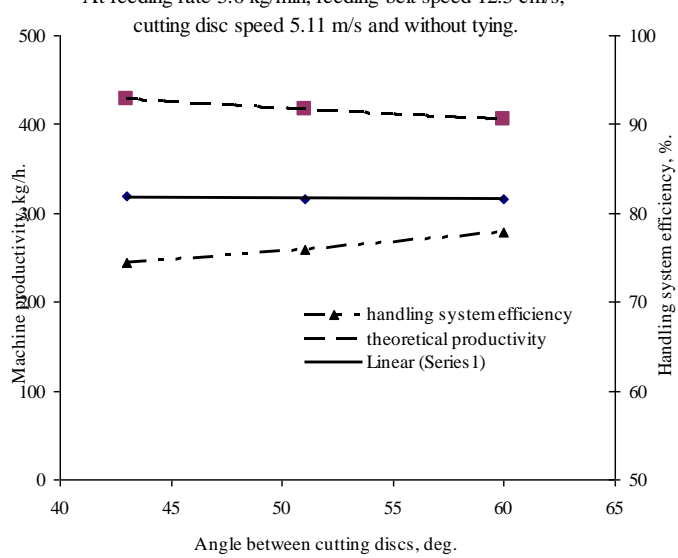

Fig. 17: Effect of angle between cutting discs on machine productivity and handling system efficiency.

At feeding rate $5.6 \mathrm{~kg} / \mathrm{min}$, feeding-belt speed $12.5 \mathrm{~cm} / \mathrm{s}$, cutting disc speed $5.11 \mathrm{~m} / \mathrm{s}$ and without tying.

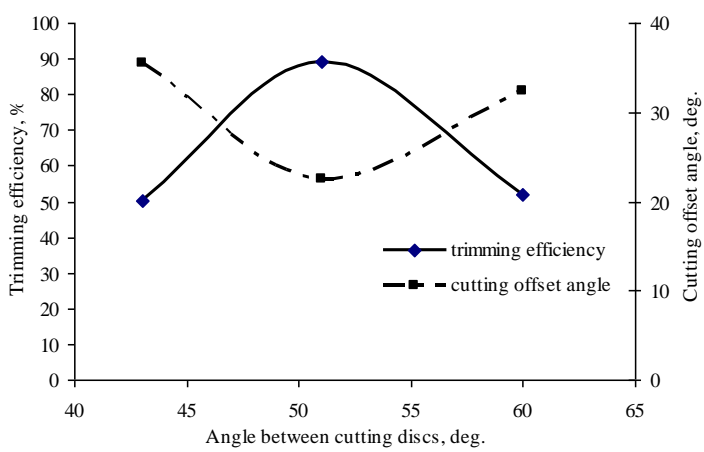

Fig. 18: Effect of angle between cutting discs on trimming efficiency and cutting offset angle.

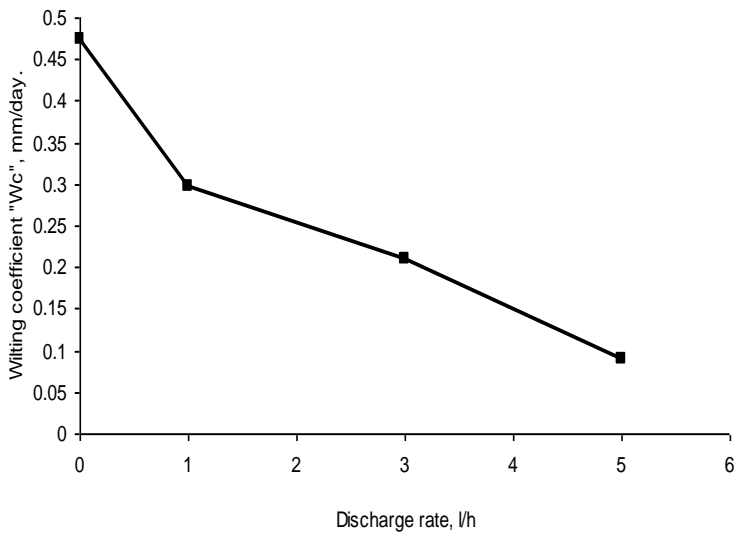

Fig. 19: Effect of discharge rate of ascorbic acid on wilting coefficient. 
Item

$\mathrm{p}$
$\mathrm{h}$
$\mathrm{y}$
$\mathrm{i}$
$\mathrm{t}$
$\mathrm{m}$
$\mathrm{W}_{1}$
$\mathrm{~W}_{2}$
$\mathrm{f}$
$\mathrm{s}$
Description

Capital investment for handling mechanism

Yearly operating hours handling mechanism

Life expectancy

Interest rate.

Taxes and overheads ratio

Maintenances and repairs ratio of the total investment

Power of cutting motor

Power of belt motor

Power unit price

Labor wage rate per month
Value

1500 L.E.

$750 \mathrm{~h}$

5 years

$12 \%$

0.05

0.1

$0.26 \mathrm{~kW}$

$0.2 \mathrm{~kW}$

0.2L.E. $/ \mathrm{kW} . \mathrm{h}$

800 L.E.

Handling mechanism productivity was $316 \mathrm{~kg} / \mathrm{h}$

The cost of handling mechanism per $\mathrm{kg}=$ cost per hour / productivity

$$
=6.47 / 316=0.021 \text { L.E. } / \mathrm{kg}=21 \text { L.E. } / \text { ton }
$$

\section{Cost for manual handling green onion:}

Assume that the handling operation (trimming, antioxidant and tying) needs one labor, with wage 800 L.E./month.

Hence, $\mathrm{C}=800 / 144=5.6$ L.E. $/ \mathrm{h}$.

Productivity for labor was $100 \mathrm{~kg} / \mathrm{h}$,

Hence, the cost of manual handling per $\mathrm{kg}=5.6 / 100$

$$
=0.056 \text { L.E. } / \mathrm{kg}=56 \text { L.E. } / \mathrm{ton}
$$

The trimming process costs by using the designed machine were 21 L.E./ton. Manual trimming one ton needs about 56 L.E. it could be said that, using the designed handling machine reduced the cost of green onion trimming to 1: 2.67 as compared with manual method.

\section{SUMMARY AND CONCLUSION}

This research was carried out to study the possibility of green onion handling processes (trimming, tying and antioxidant) and to study the factors affecting the handling processes such as feeding-belt speed, feeding rate, cutting disc speed, tying position and ascorbic acid discharge. Consequently, this research included these essential points:

1- The machine productivity was $316.2 \mathrm{~kg} / \mathrm{h}$. and handling system efficiency was $75.89 \%$ at feeding-belt speed of $12.5 \mathrm{~cm} / \mathrm{s}$. 
2- The preferred feeding rate for trimming of green onion crop was found to be $5.6 \mathrm{~kg} / \mathrm{min}$ as it resulted in lower cutting offset angle was $22^{\circ}$ and a higher trimming efficiency $89.15 \%$.

3- at cutting disc speed of $5.11 \mathrm{~m} / \mathrm{s}$ was adequate to trim the green onion crop as it resulted in higher trimming efficiency $(89.15 \%)$ and lower cutting offset angle $\left(22^{\circ}\right)$.

4- This suggests that there is little gained from the tying of bundles at position of zero up to $11 \mathrm{~cm}$. therefore ,the optimum tying position during trimming process is $7.5 \mathrm{~cm}$.

5- the optimum angle between cutting discs during trimming process is $51^{\circ}$ as it resulted in higher trimming efficiency $(89.15 \%)$ and lower cutting offset angle $\left(22^{\circ}\right)$.

6- The wilting coefficient ranged from $(0.47 \mathrm{~mm} /$ day $)$ at without antioxidant to $(0.09 \mathrm{~mm} /$ day $)$ at discharge rate of $5 \mathrm{l} / \mathrm{h}$.

7- The use of designed handling machine reduced the cost of green onion trimming to $1: 2.67$ as compared with manual method.

\section{REFERENCES}

Awady, M. N. (1978). Tractors and farm machinery. Txt. Bk. Col. Ain Shams U., P: 164-167.

E.A.S., 2004 and 2006, Economic Affairs Sector Ministry of Agric. and Land Reclamation, Agriculture Statistics.

Habib, R. A.; B. S. Azzam; G. M. Nasr and A. A. Khattab (2001) "The parameters affecting the cutting process performance of agricultural, Misr J. Ag. Eng. Vol. 19 No. (2)

Kanafojski Cz. and T. Karwowski (1976), agricultural machines, theory and construction. Vol. 2, pp. 49, foreign scientific publications.

Kepner, R.A., R.Bainer and E.L. Barger 1982, Principles of farm machinery. Third edition, pp. 315, AVI Publishing Company Inc., West Port, Connecticut, USA.

Mishra, V. K. and T.V. Gamage 2007, Postharvest Handling and Treatments of Fruits and Vegetables, pp 50 and 69, CRC Press.

Sitkei, G. (1986), Mechanics of agricultural materials, pp. 446. Elsevier Science Publishers, Amsterdam. 
Takano J. (2004), Medicinal Properties and Health Benefits of Green Onion (Scallion), http://www.pyroenergen.com/articles09/greenonions-scallion.htm

USDA, (2008), Commercial item description onions, green, fresh, readyto-use. A-A-20190B http://www.ams.usda.gov/AMSv1.0/ getfile? $\underline{\mathrm{dDoc} \text { Name }=\text { STELDEV3006931 }}$

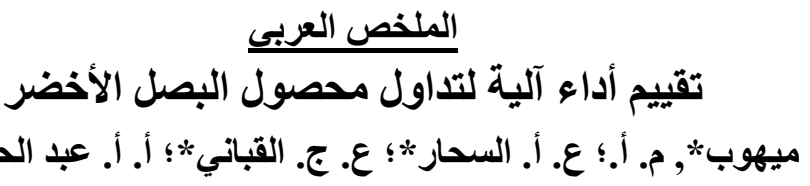

يهدف هذا البحث إلى تصميم وتقييم أداء نظام مطور لتداول محصول البصل الأخضر, بالإضـافة

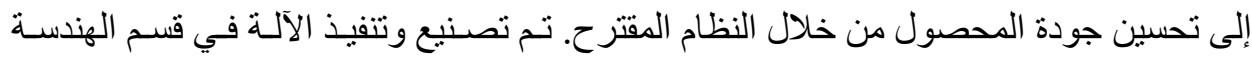

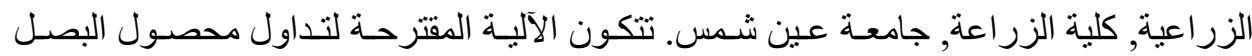
الأخضر من: سير تغذية, آلية القطع, وحدة تطهير وحدة تربيط (تحزيم). وقد تم دراسـة العوامل

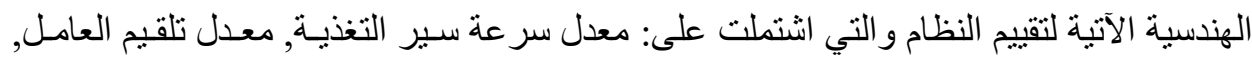

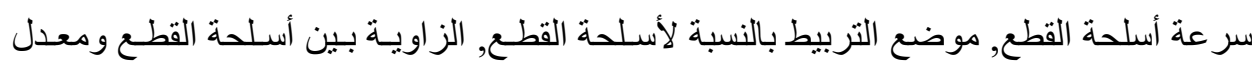

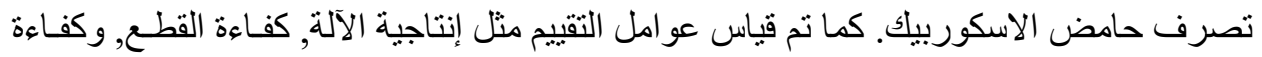
زاوية القطع. أظهرت النتائج ما يلي: زئي

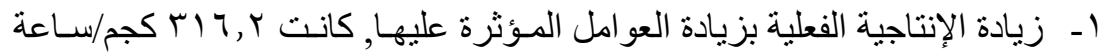

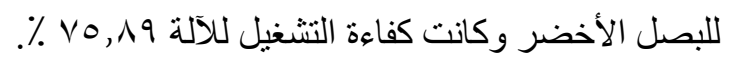

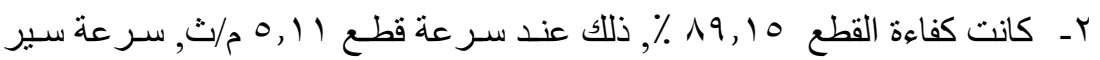

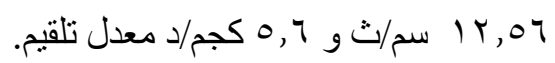

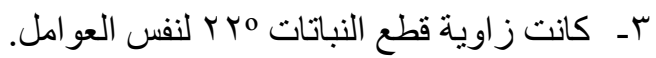

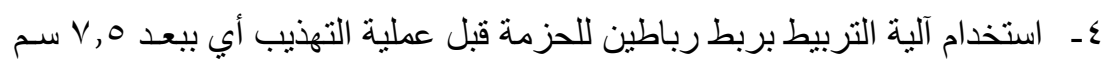

$$
\begin{aligned}
& \text { من أسلحة القطع. }
\end{aligned}
$$

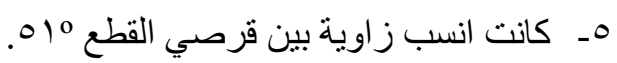

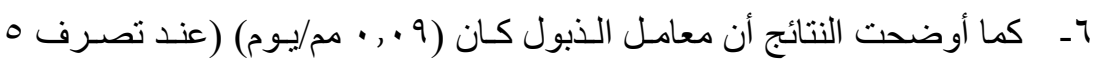

$$
\text { لتر /ساعة من حامض الاسكوربيك). }
$$

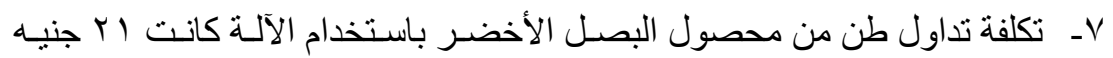

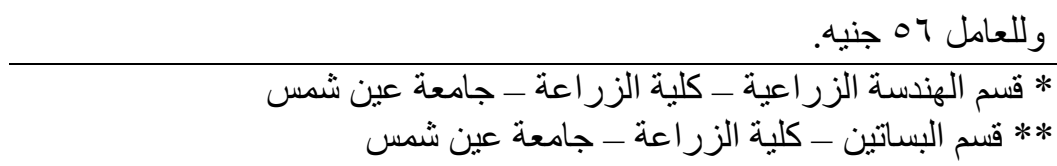

